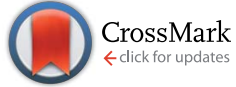

Cite this: RSC Adv., 2015, 5, 35683

\title{
Electrospinning of ultrafine metal oxide/carbon and metal carbide/carbon nanocomposite fibers $\uparrow$
}

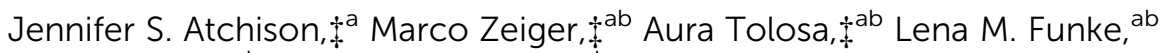 \\ Nicolas Jäckel ${ }^{\mathrm{ab}}$ and Volker Presser ${ }^{\star a b}$
}

Electrospinning has emerged as a facile technology for the synthesis of ultrafine fibers and even nanofibers of various materials. While carbon nanofibers have been extensively investigated, there have also been studies reported on metal oxide and metal carbide fibers. Yet, comparative studies, especially following the same general synthesis approach, are lacking. In our comprehensive study, we use a sol gel process by which a carrier polymer (cellulose acetate or polyvinylpyrrolidone) is mixed with titanium butoxide, zirconium(Iv) acetylacetonate, or niobium $n$-butoxide to yield nanotextured titania/carbon, zirconia/ carbon, or niobia/carbon nonwoven textiles. Carbothermal reduction between $1300{ }^{\circ} \mathrm{C}$ and $1700{ }^{\circ} \mathrm{C}$ effectively transforms the metal oxide/carbon fibers to metal carbide/carbon nanocomposite while preserving the fiber integrity. As a beneficial effect, the fiber diameter decreases compared to the asspun state and we obtained ultrafine fibers: $294 \pm 108 \mathrm{~nm}$ for ZrC/C, $122 \pm 28 \mathrm{~nm}$ for TiC/C, and $65 \pm$ $36 \mathrm{~nm}$ for $\mathrm{NbC/C}$. The highly disordered and porous nature of the carbon matrix engulfing the metal carbide nanocrystals enables a high specific surface area of up to $450 \mathrm{~m}^{2} \mathrm{~g}^{-1}$ (TiC/C) after carbothermal reduction.

Received 21st February 2015 Accepted 27th March 2015

DOI: $10.1039 / \mathrm{c} 5 \mathrm{ra05409e}$

www.rsc.org/advances storage (supercapacitors) devices. ${ }^{9}$ So far, CDCs have only been reported from $\mathrm{Si}(\mathrm{O}) \mathrm{C}$ or $\mathrm{TiC} / \mathrm{C}$ fiber mats and it is highly desirable to have an array of metal carbide/carbon nanocomposite fiber compositions available. Thus, the scope of this work is to establish in addition to optimized TiC/C fibers also $\mathrm{ZrC} / \mathrm{C}$ and $\mathrm{NbC} / \mathrm{C}$ as freestanding nonwoven textiles following a sol gel approach.

The best investigated electrospun metal carbide fiber system to date is silicon carbide, mostly derived from polycarbosilane ${ }^{\mathbf{1 0}}$ or polycarbomethylsilane. ${ }^{\mathbf{1 1}}$ Commonly, such fibers are in the micrometer range, ${ }^{\mathbf{1 1}, \mathbf{1 2}}$ although fiber diameters as small as $c a$. $500 \mathrm{~nm}$ have been reported recently when using polymethylphenylsilsesquioxane and polyvinylpyrrolidone as carrier polymer. ${ }^{13}$ The low annealing temperatures at or below $1000{ }^{\circ} \mathrm{C}$ result in a silicon carbide that lacks the formation of an important feature of MCCs, namely carbide nanocrystals engulfed in a matrix of highly porous, partially graphitic carbon. $^{7}$

$\mathrm{TiO}_{2} / \mathrm{C}$ and $\mathrm{TiC} / \mathrm{C}$ ultrafine fibers have been electrospun from preformed $\mathrm{TiO}_{2}$ nanoparticles (e.g., derived from titanium isopropoxide or $\mathrm{TiCl}_{4}$ ) and a carrier polymer. ${ }^{\mathbf{1 4}}$ Alternatively, nanofibers have been successfully electrospun from solutions containing a sol and a carrier polymer, growing in situ a metal oxide network that was later carbothermally reduced to metal carbide. The smooth ultrafine $\mathrm{TiO}_{2} / \mathrm{C}$ fibers and nanofibers have also been reported by electrospinning a mixture containing polyvinylpyrrolidone (PVP) with a sol using titanium isopropoxide as the metal precursor, with the

${ }^{a} I N M$ - Leibniz Institute for New Materials, Campus D2 2, 66123 Saarbrücken, Germany. E-mail: volker.presser@inm-gmbh.de

${ }^{b}$ Saarland University, Campus D2 2, 66123 Saarbrücken, Germany

$\dagger$ Electronic supplementary information (ESI) available. See DOI: 10.1039/c5ra05409e

\$ These authors contributed equally. 
addition of acetic acid or acetylacetonate as stabilizers. ${ }^{\mathbf{4 , 1 5 , 1 6}}$ The obtained fibers presented diameters between $50-250 \mathrm{~nm}$, but had a low specific surface area of $68-70 \mathrm{~m}^{2} \mathrm{~g}^{-\mathbf{1}} \cdot{ }^{\mathbf{1 4 1} 17} \mathrm{In}$ addition, TiC/C composite and TiC-CDC with non-uniform morphology including beaded fibers and average diameters around 100-120 $\mathrm{nm}$ have been produced using a phenolic resin and $\mathrm{TiCl}_{4}$, as carbon and metal sources, respectively, exhibiting a high surface area of $523 \mathrm{~m}^{2} \mathrm{~g}^{-1}$ for the MCC. ${ }^{18}$ Also, ultrafine fibers and ribbons with $300 \mathrm{~nm}$ width and 40 $\mathrm{nm}$ thickness have been obtained by electrospinning titanium(Iv) $n$-butoxide and furfuryl alcohol as titanium and carbon sources, respectively. ${ }^{6}$ Based on this approach, in our previous study smooth TiC ultrafine fibers $(131 \mathrm{~nm})$ and TiCCDC were obtained with the same fiber diameter. ${ }^{7}$

Zirconia fibers with diameters between 50-1000 nm have been produced by electrospinning mixtures containing a carrier polymer and a metal oxide precursor followed by calcination between $540{ }^{\circ} \mathrm{C}$ and $930{ }^{\circ} \mathrm{C} .{ }^{19}$ Several routes have been proposed, using zirconium(Iv) oxychloride octahydrate, ${ }^{\mathbf{1 9 , 2 0}}$ zirconium(Iv)isopropoxide, ${ }^{\mathbf{2 1}}$ or zirconium(Iv)acetylacetonate (ZrAcAc) ${ }^{22}$ as metal oxide sources. Composite ZrC/C ultrafine fibers have been only obtained by electrospinning sol gel systems containing ZrAcAc with a carbon precursor which also acts as a carrier polymer, mixed for $\mathrm{C} / \mathrm{Zr}$ ratios higher than 3 to produce stoichiometric $\mathrm{ZrC}{ }^{23,24}$ The thinnest ZrC fibers obtained so far measured $730 \mathrm{~nm}$ in diameter after annealing at $1600{ }^{\circ} \mathrm{C},{ }^{23}$ using ZrAcAc, cellulose acetate as carbon source, and acetic acid to stabilize the sol. Instead of using a sol gel approach, recently Li et al. reported thinner fibers by electrospinning polyzirconoxane with a primary carbon source (PAN or sucrose) ${ }^{25}$ After annealing at $1400{ }^{\circ} \mathrm{C}$, fiber diameters around 1-2 $\mu \mathrm{m}$ were reported for PAN and 500-600 $\mathrm{nm}$ for a mixture of PAN and sucrose. Thus, $500 \mathrm{~nm}$ diameter remains as a limit for the current state-ofthe-art of $\mathrm{ZrC} / \mathrm{C}$ fibers.

Mixing pre-existing niobium oxide nanoparticles with poly(vinyl alcohol) (PVA) with niobia, niobium carbide fibers have been produced by electrospinning. ${ }^{26} \mathrm{~A}$ thermal treatment at $1500{ }^{\circ} \mathrm{C}$ produces $\mathrm{NbC}$ fibers of about $110 \mathrm{~nm}$ diameter and a low surface area $\left(4 \mathrm{~m}^{2} \mathrm{~g}^{-1}\right)$ by annealing at $800{ }^{\circ} \mathrm{C}$ was observed. The synthesis of ultrafine $\mathrm{Nb}_{2} \mathrm{O}_{5}$ fibers by sol gel and electrospinning has been reported by mixing niobium $n$-butoxide ${ }^{27}$ or niobium ethoxide ${ }^{28}$ with a dissolved carrier polymer and an acid catalyst. As reported by Macias et al. when using $\mathrm{HCl}$ as the acid catalyst, ultrafine fibers $(400-600 \mathrm{~nm})$ were obtained $;{ }^{27}$ however, the fiber mats lost structural integrity upon calcination. Viswanathamurthi et al. reported ultrafine fibers $(500 \mathrm{~nm})$ by adding acetic acid, which acted as a catalyst for the hydrolysis and condensation reaction; the latter also formed a complex with niobium ethoxide which retarded the reaction and effectively prevented precipitation. ${ }^{28}$ This way, electrospinning was possible, but only during such a small time window that no suitable mats were obtained. Thus, until now, there has been no report of a sol-gel-approach of forming a niobium carbide phase without already starting with admixed niobia nanoparticles.
In this study, we present data for $\mathrm{TiC} / \mathrm{C}, \mathrm{NbC} / \mathrm{C}$, and $\mathrm{ZrC} / \mathrm{C}$ nanocomposites fibers with partially unprecedented small diameters compared to the state-of-the-art. While we build on the previously reported synthesis of TiC/C via carbothermal reduction of $\mathrm{TiO}_{2} / \mathrm{C}$ nanofibers, we present a novel chemistry system to electrospin $\mathrm{NbC} / \mathrm{C}$ and $\mathrm{ZrC} / \mathrm{C}$ nanocomposites for a non-woven textile solely employing sol gel synthesis as a versatile technology platform. Thus, we abstain from adding metal oxide nanoparticles. Instead, metal oxide nanodomains within the electrospun fibers are formed in an in situ synthesis approach. Presenting these three related synthesis routes sideby-side, we provide a comprehensive technology platform to build on for further technological exploitation of these unique nanocomposite fibers, for example, as electrodes for supercapacitors, capacitive deionization, or other electrochemical applications.

\section{Experimental}

\subsection{Materials}

All chemicals were used as received. Zirconium(Iv)acetylacetonate $(\mathrm{Zr}(\mathrm{Iv}) \mathrm{AcAc})$ and titanium butoxide (Ti(Iv)BO) were purchased from Sigma-Aldrich. Niobium $n$-butoxide (NbBO) was purchased from Alfa Aesar. Carrier polymers cellulose acetate (CA) and polyvinylpyrrolidone (PVP) were purchased from Sigma-Aldrich as well the following solvents: acetylacetone (AcAc), anhydrous dimetylformamide $99.8 \%$ purity (DMF), acetic acid (AA), acetic anhydride $\left(\mathrm{Ac}_{2} \mathrm{O}\right)$, and furfuryl alcohol (FA). Air-sensitive materials ( $\mathrm{NbBO}, \mathrm{AA}$, and $\mathrm{Ac}_{2} \mathrm{O}$ ) were stored in an inert gas atmosphere under nitrogen in a glove box.

\subsection{Fiber synthesis}

Fibers mats were electrospun using a MECC Co. NF-103V nanofiber system. Each sol-polymer system used slightly different spinning parameters due to variations in solution properties. All samples were spun on a stationary grounded target wrapped with aluminum foil. The spinneret head moved with respect to the collector along the $x$-axis parallel to the collector (travel distance). In addition, the head moved along the $z$-axis, perpendicular to the collector, which adjusts the distance from the spinneret tip to the collector or the distance the fiber flies (fly distance). The velocity of the head traveling in the $x$-axis can be defined as the travel velocity and is reported in $\mathrm{mm} \mathrm{s}^{-1}$. A variable pump rate $\left(\mathrm{mL} \mathrm{h}^{-1}\right)$ is used to supply the spin dope to the spinneret. Finally, the temperature and relative humidity were monitored by a portable thermometer-hygrometer. More specific parameters for each system are summarized in Table 1 and shortly outlined below.

The TiBO sol precursor was prepared adopting the method established by Zhang et al. ${ }^{6}$ In short, the sol was prepared in ambient conditions by mixing the liquids TiBO, FA, AA, and DMF in a mass ratio of $1: 1: 0.25: 6.75$; then, $1 \mathrm{~g}$ of PVP is added to this mixture to make a 10 mass $\%$ solution. The mixture is aged while stirring for $48 \mathrm{~h}$ at room temperature. The final solution is translucent amber color with a viscosity of $0.27 \mathrm{~Pa} \mathrm{~s}$ at a shear rate of $500 \mathrm{~s}^{-1}$. Fibers were spun under the 
Table 1 Synthesis parameters for electrospinning of metal carbide/ carbon nanocomposites fibers

\begin{tabular}{llll}
\hline & & & ZrAcAc + \\
Parameter & TiBO + PVP & NbBO + PVP & cellulose acetate \\
\hline Applied voltage $(\mathrm{kV})$ & 15 & 23 & 20 \\
Fly distance $(\mathrm{mm})$ & 250 & 165 & 250 \\
Pump rate $\left(\mathrm{mL} \mathrm{h}^{-1}\right)$ & 0.2 & 0.5 & 0.5 \\
Travel speed $\left(\mathrm{mm} \mathrm{s}^{-1}\right)$ & 50 & 0 & 30 \\
Travel distance $(\mathrm{mm})$ & 100 & 0 & 200 \\
Temperature $\left({ }^{\circ} \mathrm{C}\right)$ & 23 & 25 & 26 \\
Relative humidity & $21-32$ & $11-15$ & $21-25$ \\
& & & \\
\hline
\end{tabular}

influence of a $15 \mathrm{kV}$ potential. The collected fibers were allowed to age an additional $72 \mathrm{~h}$ exposed to ambient relative humidity (32 to $45 \%$ ) to encourage hydrolysis and the formation of an extended metal-oxygen-metal network. Carbothermal reduction to convert metal oxides to carbides was accomplished by a two-step heat treatment profile under $99.5 \%$ argon in a Thermal Technologies furnace. The TiBO complex fibers were heated to $325{ }^{\circ} \mathrm{C}$ at $5{ }^{\circ} \mathrm{C} \mathrm{min}^{-1}$ and annealed at that temperature for $3 \mathrm{~h}$. The second step of the temperature profile is a $5{ }^{\circ} \mathrm{C} \mathrm{min}^{-1}$ ramping to $1400{ }^{\circ} \mathrm{C}$. At this temperature, TiC is thermodynamically favored over $\mathrm{Ti}-\mathrm{O}$ in the presence of excess carbon from the pyrolyzed PVP and FA. ${ }^{29}$ The reaction is completed in 5 $\mathrm{h}$ and the carbide/carbon nanocomposite nonwoven textile is cooled to room temperature.

Zirconium carbide/carbon nanocomposite textiles were produced from a precursor of cellulose acetate in $10 \mathrm{~mL}$ of $1: 1$ by volume AA to AcAc (16 mass\% polymer) allowed to solvate overnight until the solution was optically transparent. To this $5 \mathrm{~g}$ of $\mathrm{Zr}(\mathrm{Iv}) \mathrm{AcAc}$ was added and mixed for $24 \mathrm{~h}$ until the solution was optically transparent and the viscosity reached $0.93 \mathrm{~Pa}$ s at a shear rate of $500 \mathrm{~s}^{-1}$. The solution was electrospun at $20 \mathrm{kV}$ and subjected to a 2-step heat treatment regime. The $\mathrm{Zr}$ complex textiles were heated at $5{ }^{\circ} \mathrm{C} \min ^{-1}$ to $350{ }^{\circ} \mathrm{C}$ and held at temperature for $3 \mathrm{~h}$ to stabilize the fibers then heated up at $5{ }^{\circ} \mathrm{C}$ $\min ^{-1}$ to $1500{ }^{\circ} \mathrm{C}$ and held at temperature for $2 \mathrm{~h}$ then cooled to room temperature. ${ }^{23}$

The precursor sol for niobium oxide was prepared under nitrogen to prevent premature gelation. In this preparation, $\mathrm{NbBO}$ was mixed with $\mathrm{Ac}_{2} \mathrm{O}(2.47 \mathrm{~mL}: 0.55 \mathrm{~mL})$, and stirred for $60 \mathrm{~s}$. To this, $25 \mathrm{~mL}$ of DMF and $3 \mathrm{~g}$ of PVP were added and mixed for $48 \mathrm{~h}$ until the solution was translucent while exhibiting a viscosity of $0.032 \mathrm{~Pa}$ at a shear rate of $500 \mathrm{~s}^{-1}$. The solution was electrospun under an applied potential of $23 \mathrm{kV}$. The niobium complex fibers were allowed to age in ambient humidity to promote condensation of the metal oxide domains for $72 \mathrm{~h}$ prior to heat treatment. The same furnace was used for the two-step temperature profile as was used for the other syntheses using an annealing temperature of $400{ }^{\circ} \mathrm{C}$ for $3 \mathrm{~h}$ with a $5{ }^{\circ} \mathrm{C} \mathrm{min}{ }^{-1}$ heating rate. For the carbothermal reduction heat treatment study, the pyrolyzed fibers were subjected to a high temperature annealing at $1100,1300,1500$, or $1700^{\circ} \mathrm{C}$ for $4 \mathrm{~h}$ with a $5^{\circ} \mathrm{C} \mathrm{min}^{-1}$ heating rate. One carbon/niobia sample was processed under each temperature profile for a total of 4 samples. In addition, one sample was heat treated at $400{ }^{\circ} \mathrm{C}$ for $3 \mathrm{~h}$ for characterization of the stabilized oxide fibers.

\subsection{Characterization methods}

The fibers were imaged using a FEI ESEM Quanta 400 FEG scanning electron microscope (SEM) under variable pressure and a JEOL JSM 7500F field emission scanning electron microscope (FESEM). Non-conductive samples were coated with a nanoscopically thin layer of $\mathrm{Au}$ or $\mathrm{Pt} / \mathrm{Au}$. ImageJ software was used to process the SEM images and diameters of at least 150 fibers were measured. ${ }^{30}$ Cross sectional focused ion beam cutting was performed with a Helios Nanolab 600 (FEI) using a working distance of $4 \mathrm{~mm}$, a dwell time of $1 \mu \mathrm{s}$, and a cutting depth of $1 \mu \mathrm{m}$. Before cutting the sample was sputter coated with platinum for stabilization. High-resolution transmission electron (TEM) micrographs of the fibers were recorded after dispersing fibers in ethanol via sonication for $5 \mathrm{~min}$ and placing the solution over a copper grid with a lacey carbon film and imaging with a JEOL $2100 \mathrm{~F}$ TEM operated at $200 \mathrm{kV}$.

Infrared vibrational spectroscopy was performed with an attenuated total internal reflectance crystal (ATR) attachment on a Bruker Tensor 27 FTIR (Fourier-transform infrared) and spectra were integrated over 28 scans. Raman spectra were measured using a Renishaw inVia Raman system equipped with an Nd-YAG laser and an excitation wavelength of $532 \mathrm{~nm}$ with power of $0.2 \mathrm{~mW}$ at the focal point focused on a spot of $c a .2 \mu \mathrm{m}$ diameter. A grating with 2400 lines per $\mathrm{mm}$ and a $50 \times$ objective (numeric aperture: 0.9) was used, yielding a spectral resolution of $1.2 \mathrm{~cm}^{-1}$. Peak fitting was accomplished assuming two Lorentzian peaks, one for the D-mode and one for the G-mode, respectively.

The free carbon content was measured using a VG Scienta furnace system, applying $700{ }^{\circ} \mathrm{C}$ for $1 \mathrm{~h}$ with a heating rate of $20^{\circ} \mathrm{C} \mathrm{min}^{-1}$ in synthetic air. The mass before and after thermal treatment was measured to calculate the initial carbon content.

A Bruker AXS D8 Advance diffractometer was used to collect $\mathrm{X}$-ray diffractogramms using $\mathrm{Cu}-\mathrm{K} \alpha$ radiation $(0.15418 \mathrm{~nm})$ with a step size of $0.02^{\circ}$ and a measurement time of $1 \mathrm{~s} \mathrm{per} \mathrm{step.} \mathrm{The}$ system was calibrated with $\mathrm{LaB}_{6}$ single crystal prior to each measurement. Rietveld analysis was employed to determine lattice parameters and average coherence length values (corresponding roughly with the crystal domain size) using TOPAS software from Bruker.

Nitrogen gas sorption measurements at $-196{ }^{\circ} \mathrm{C}$ were carried out with an Autosorb iQ system (Quantachrome). The samples were outgassed at $150{ }^{\circ} \mathrm{C}$ for $10 \mathrm{~h}$ under vacuum conditions (100 Pa) to remove adsorbed water and other surface functionalities. Nitrogen gas sorption was performed in liquid nitrogen in the relative pressure range from $5 \times 10^{-7}$ to 1.0 in 68 steps. The specific surface area (SSA) was calculated with the ASiQwin-software using the Brunauer-Emmett-Teller (BET) equation in the linear relative pressure range 0.01-0.20.

Sol viscosities were measured using a modular compact Physica rheometer from Anton Paar with a $49.94 \mathrm{~mm} 1^{\circ}$ cone and plate configuration. The sample chamber was left open to 
ambient humidity and viscosities were measured at constant shear rate of $500 \mathrm{~s}^{-1}$.

\section{Results and discussion}

\subsection{Titanium carbide/carbon nanocomposite fibers}

As-spun ultrafine fibers obtained from the TiBO precursor shown in Fig. 1A exhibit a smooth surface morphology and show an average diameter of $264 \pm 53 \mathrm{~nm}$ (Fig. 2A). The fibers maintained their morphology after pyrolysis in argon at $325{ }^{\circ} \mathrm{C}$ for $3 \mathrm{~h}$ (Fig. 1B), but the fiber diameters were reduced by $18 \%$ to $217 \pm 49 \mathrm{~nm}$ (Fig. 2A). The low temperature heat treatment stabilized the fiber morphology by promoting the FA to polymerize, evolved off water and organic residuals, and drove condensation and formation of an oxydic network. ${ }^{29}$ Subsequent carbothermal reduction in argon at $1400{ }^{\circ} \mathrm{C}$ for $5 \mathrm{~h}$ produced fibers with irregular oblate morphologies as seen in Fig. 1C and D with mean fiber diameters of $122 \pm 28 \mathrm{~nm}$ (Fig. 2A) and this value aligns very well with our previous study (i.e., $131 \pm 52 \mathrm{~nm}$ ). ${ }^{7}$ As an important feature, we note that the open architecture afforded by the nonwoven fibers is preserved throughout the heat treatment process and the final textile is mechanically stabilized because the fiber crossovers are sintered together forming an isotropic percolated network of
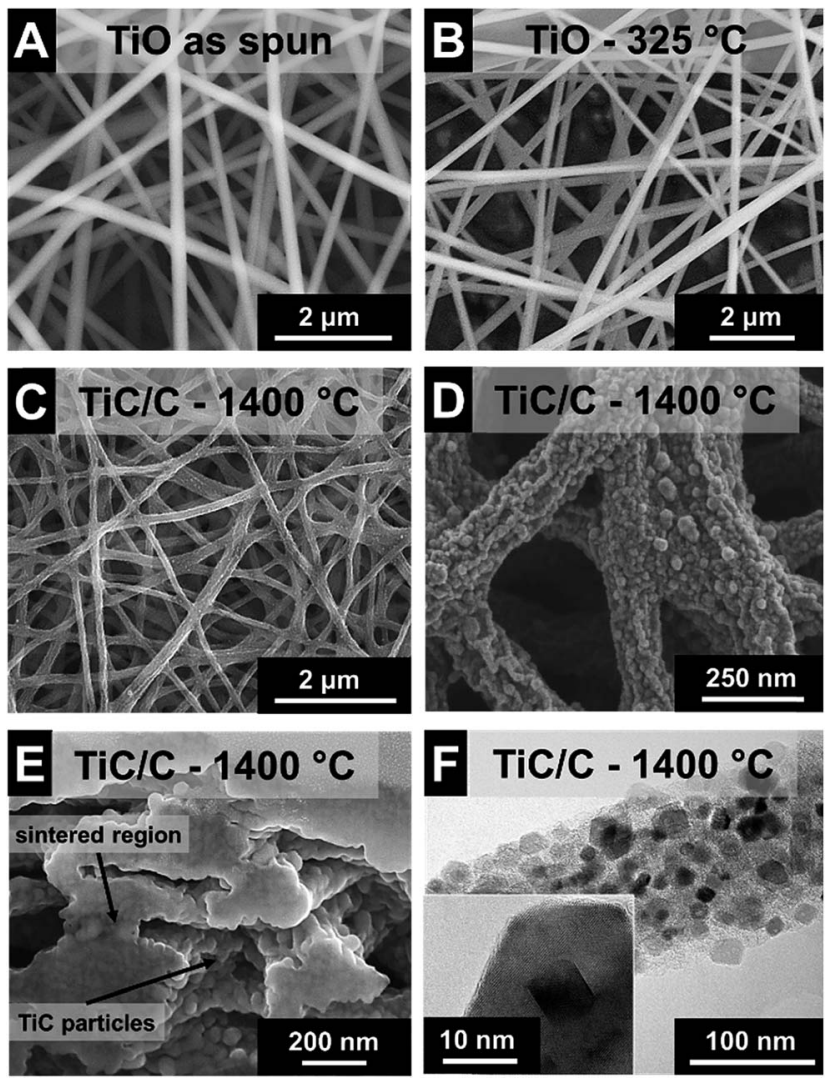

Fig. 1 Scanning (A-E) and transmission (F) electron micrographs of final TiC/C nanocomposite fibers. (A) As spun. (B) After heat treatment in argon at $325^{\circ} \mathrm{C}$ for $3 \mathrm{~h}$. (C-F) After heat treatment in argon at $1400^{\circ} \mathrm{C}$ for $5 \mathrm{~h}$. titanium carbide nanocrystals and carbon (Fig. 1E). This way, free-standing fiber mats are obtained.

TEM investigation shows that the fibers were nanocomposites composed of TiC nanocrystals embedded in a continuous network of disordered carbon in a brick-andmortar-like fashion (Fig. 1F). The rough fiber morphology is a result of the nanoscopic character of the carbide nanocrystals with a size of $c a$. $20 \mathrm{~nm}$ which are engulfed by 1-3 layers of disordered carbon (Fig. 1F). As determined from high resolution TEM, the corresponding lattice spacing of $0.25 \mathrm{~nm}$ is characteristic for the (111) $d$-spacing of TiC. We also note that the fibers do not show any tendency for core-shell formation but instead exhibit a very homogenous texture throughout the fiber (Fig. 1F). The isotherm measured using gas sorption analysis shows a typical combination between type I and II characteristic for micro- and macroporous materials (ESI; Fig. S1A $\dagger$ ). The combination of fully dense carbide nanocrystals and disordered porous carbon yields a rather high specific surface area (SSA) of $450 \mathrm{~m}^{2} \mathrm{~g}^{-1}$ (Table 2). This value is slightly higher than what we have reported before for this system $\left(+10 \%\right.$; i.e., $414 \mathrm{~m}^{2} \mathrm{~g}^{-1}$; ref. 7$)$ and somewhat smaller than what has recently been reported by the Kaskel group (namely, $523 \mathrm{~m}^{2} \mathrm{~g}^{-1}$; ref. 18). For comparison, we note that a fully dense TiC nanofiber of the same average diameter would only show a SSA of $10 \pm 3 \mathrm{~m}^{2} \mathrm{~g}^{-1}$ which illustrates the large pore volume maintained within the carbon phase. In our system the free carbon content was measured to 32 mass\% (Table 2). Considering the non-porous nature of TiC nanocrystals, we can estimate a porosity of the amorphous carbon phase of more than $1400 \mathrm{~m}^{2} \mathrm{~g}^{-1}$.

Raman spectroscopy confirmed the presence of free carbon in the fibers, that is, carbon that is not bound in form of the metal carbide (Fig. 2B, Table 2). Free carbon is in a highly disordered state and stems from FA, AA, and BO residuals forming a cohesive matrix around TiC nanocrystals, as seen in Fig. 1F. The two dominant features in the Raman spectrum, namely the band at $1341 \pm 0.1 \mathrm{~cm}^{-1}$ (FWHM: $98 \pm 0.9 \mathrm{~cm}^{-1}$ ) and the band at $1598 \pm 0.5 \mathrm{~cm}^{-1}$ (FWHM: $58 \pm 0.4 \mathrm{~cm}^{-1}$ ) are assigned to the D-mode and G-mode of carbon, respectively. ${ }^{31}$ The integral intensity ratio, $I_{\mathrm{D}} / I_{\mathrm{G}}$, is a metric of carbon ordering and the high value of $2.1 \pm 0.1$ is indicative of incompletely graphitized carbon ${ }^{32}$ and typical for nanoporous carbon materials. ${ }^{33}$ In contrast to carbon, the other component of the ultrafine fibers, titanium carbide, is present in a highly crystalline phase. The TiC nanocrystals can be assigned to the space group $F m \overline{3} m$ with a lattice spacing of $0.431 \mathrm{~nm}(c f$. PDF-32-1383: $0.433 \mathrm{~nm}) .^{34}$ In more detail, X-ray diffraction (Fig. 2C) confirms the nanocrystalline character of titanium carbide. Rietveld analysis for samples after carbothermal reduction for $5 \mathrm{~h}$ in argon yields a value of $22 \mathrm{~nm}$, which is in perfect agreement with the TEM observations (Fig. 1F).

To better understand the evolution of the oxide network formation, FTIR spectroscopy was carried out on the as-spun fibers and the precursor (Fig. 2D). The sol was investigated without PVP and DMF and the main interaction in the sol is between TiBO and acetic acid. The acid slows down the condensation by coordinating with titanium ions. FTIR 

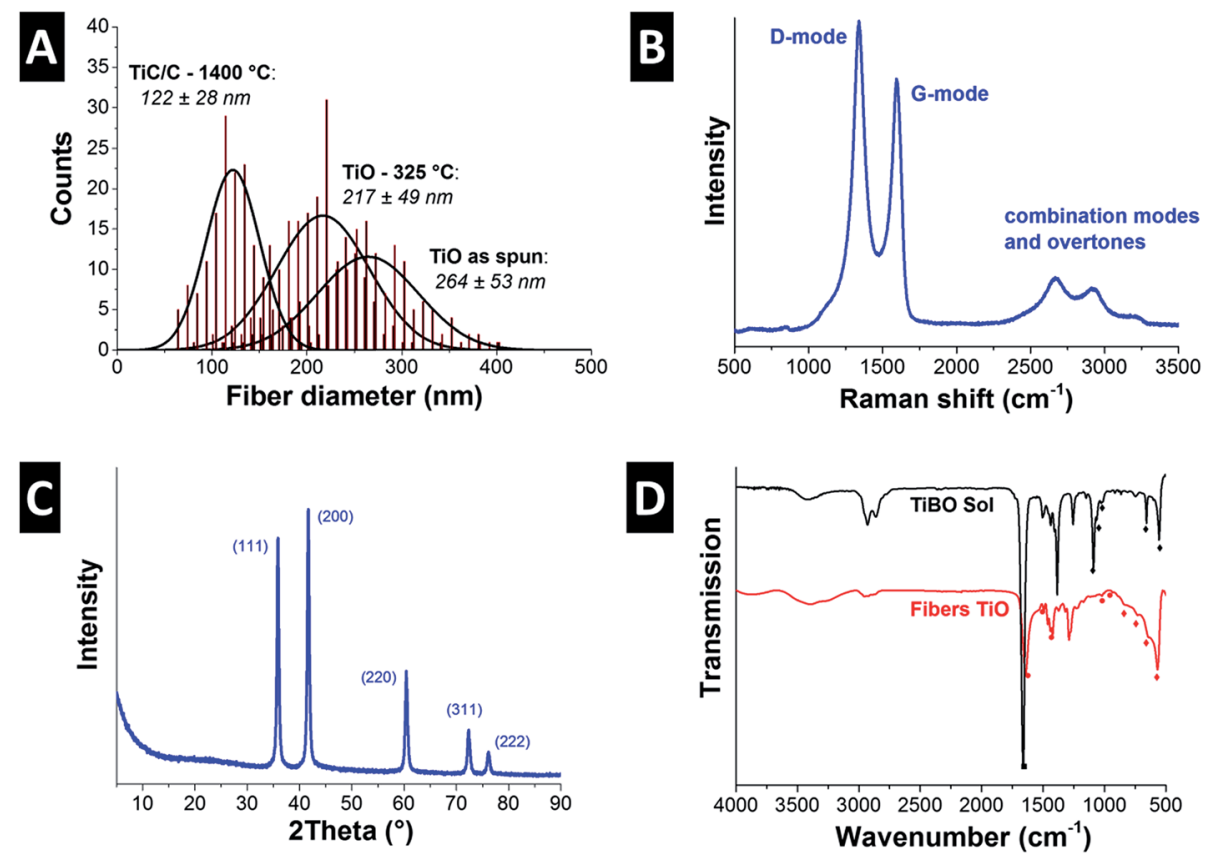

Fig. 2 (A) Fiber diameter distributions of the as spun TiO fibers and heat treated fibers at $325^{\circ} \mathrm{C}$ and $1400{ }^{\circ} \mathrm{C}$. (B) Raman spectrum of TiC/C, and (C) X-ray diffractogram of the TiC/C nanocomposite fibers after heat treatment in argon at $1400{ }^{\circ} \mathrm{C}$ for $5 \mathrm{~h}$, and (D) FTIR spectra of the TiBO sol and the as spun fibers.

spectra of the AA-TiBO-FA show bands near $1665 \mathrm{~cm}^{-1}(\mathrm{C}=\mathrm{O}$ stretch) from the $\mathrm{AA}$ and absorption bands between $1150-900 \mathrm{~cm}^{-1}$ assigned to the $\mathrm{C}-\mathrm{O}$ terminal vibration arising from the $\mathrm{Ti}-\mathrm{O}-\mathrm{C}_{4} \mathrm{H}_{9}$ mixed with bridging $\mathrm{Ti}-\mathrm{C}-\mathrm{O}$ vibrations at $1023 \mathrm{~cm}^{-1}$ and $912 \mathrm{~cm}^{-1}$. Other peaks can be assigned to the formation of $\mathrm{M}-\mathrm{O}$ below $800 \mathrm{~cm}^{-1}$. In particular, the combination of peaks at $3410 \mathrm{~cm}^{-1}(\mathrm{O}-\mathrm{H})$ and $950 \mathrm{~cm}^{-1}$ are evidence of butanol formed as a reaction product. ${ }^{35,36}$ During electrospinning, the DMF and acetic acid evaporate from the fibers leaving behind PVP and a nascent titanium oxide network (Fig. 2D). In addition, the peaks between $1500 \mathrm{~cm}^{-1}$ and $1400 \mathrm{~cm}^{-1}$ are assigned to the $\mathrm{CH}_{2}$ scissoring vibrations on the PVP rings, while the small peak at $1016 \mathrm{~cm}^{-1}$ corresponds to the $\mathrm{C}-\mathrm{C}$ polymer backbone, and the band at $930 \mathrm{~cm}^{-1}$ is the breathing mode of the ring. ${ }^{37}$ The very broad peaks below $800 \mathrm{~cm}^{-1}$ are related to the $\mathrm{O}-\mathrm{Ti}-\mathrm{O}$ network. ${ }^{35}$ This amorphous oxygen-metal-oxygen network evolves at higher temperatures to the TiC nanocrystals via carbothermal reduction.

\subsection{Zirconium carbide/carbon nanocomposite fibers}

The cylindrical fibers electrospun from $\operatorname{Zr}(\mathrm{Iv}) \mathrm{AcAc}$ and CA in a solution of AA/AcAc show a very smooth morphology without beads or other visible defects (Fig. 3A). Unlike the fibers spun from the TiBO precursor, the $\operatorname{Zr}(\mathrm{Iv}) \mathrm{AcAc}$ precursor yielded significantly higher fiber diameters, namely $715 \pm 395 \mathrm{~nm}$. The larger diameter is a result of the higher polymer content necessary to produce uniform fibers. Lower polymer content solutions resulted in extensive beading and low quality nonwoven textiles were obtained. However, the large standard deviation in fiber diameters is reflective of a broad size distribution, ranging from a population of very fine fibers smaller than $200 \mathrm{~nm}$ up to larger sized fibers with more than $2 \mu \mathrm{m}$ (Fig. 4A).

Table 2 Overview of the results of free carbon content measurements, gas sorption analysis using BET equation, and Raman peak analysis for the metal carbide/carbon nanocomposites fibers. The free carbon mass was determined gravimetrically by oxidation of the MCC material

\begin{tabular}{|c|c|c|c|c|c|}
\hline \multirow[b]{2}{*}{ Sample } & \multirow[b]{2}{*}{ Free carbon mass $\%$} & \multirow[b]{2}{*}{ BET SSA $\left(\mathrm{m}^{2} \mathrm{~g}^{-1}\right)$} & \multirow[b]{2}{*}{$I_{\mathrm{D}} / I_{\mathrm{G}}$-ratio } & \multicolumn{2}{|c|}{ FWHM $\left(\mathrm{cm}^{-1}\right)$} \\
\hline & & & & D-mode & G-mode \\
\hline $\mathrm{TiC} / \mathrm{C}-1400^{\circ} \mathrm{C}$ & 32 & 450 & $2.1 \pm 0.1$ & $98 \pm 0.9$ & $58 \pm 0.4$ \\
\hline $\mathrm{ZrC} / \mathrm{C}-1500{ }^{\circ} \mathrm{C}$ & 15 & 224 & $1.7 \pm 0.0$ & $66 \pm 3.6$ & $63 \pm 2.2$ \\
\hline $\mathrm{NbC} / \mathrm{C}-1100^{\circ} \mathrm{C}$ & 15 & 151 & $2.6 \pm 0.0$ & $148 \pm 1.6$ & $60 \pm 0.3$ \\
\hline $\mathrm{NbC} / \mathrm{C}-1300^{\circ} \mathrm{C}$ & 19 & 147 & $1.9 \pm 0.3$ & $94 \pm 1.0$ & $64 \pm 6.5$ \\
\hline $\mathrm{NbC} / \mathrm{C}-1500^{\circ} \mathrm{C}$ & 20 & 121 & $2.0 \pm 1.0$ & $67 \pm 0.7$ & $60 \pm 10.7$ \\
\hline $\mathrm{NbC} / \mathrm{C}-1700^{\circ} \mathrm{C}$ & 29 & 39 & $1.2 \pm 0.2$ & $53 \pm 0.4$ & $57 \pm 4.8$ \\
\hline
\end{tabular}



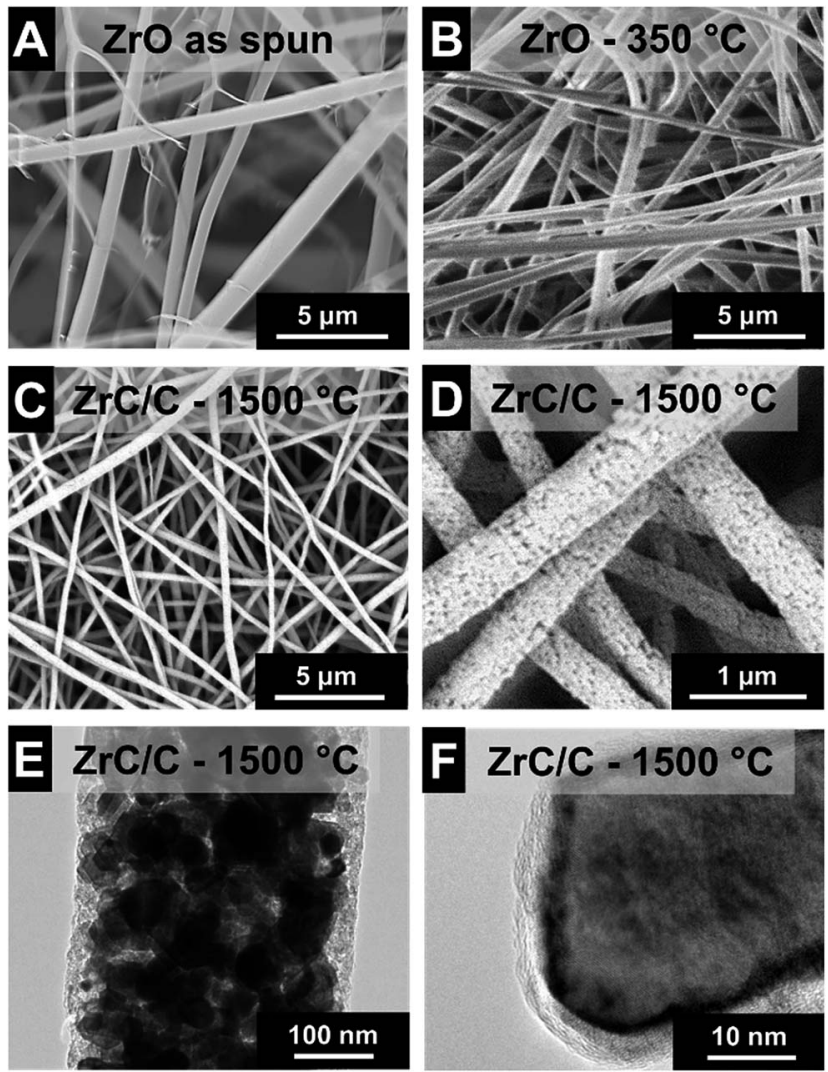

Fig. 3 Scanning (A-D) and transmission ( $E$ and $F$ ) electron micrographs of final $\mathrm{ZrC} / \mathrm{C}$ nanocomposite fibers. (A) As spun. (B) After heat treatment in argon at $350{ }^{\circ} \mathrm{C}$ for $3 \mathrm{~h}$. (C-F) After heat treatment in argon at $1500{ }^{\circ} \mathrm{C}$ for $2 \mathrm{~h}$.
Pyrolysis was accomplished via heat treatment at $350{ }^{\circ} \mathrm{C}$ for $3 \mathrm{~h}$ under argon resulting in a $26 \%$ reduction of the mean fiber diameter (Fig. 3B and 4A). During the heat treatment, some of the smaller fibers were consumed and the remaining population has a mean diameter of $531 \pm 171 \mathrm{~nm}$. Carbothermal reduction at $1500{ }^{\circ} \mathrm{C}$ for $2 \mathrm{~h}$ produced fibers with very rough surfaces and an average size of $294 \pm 108 \mathrm{~nm}$ corresponding to a $59 \%$ reduction compared to the as spun fibers (Fig. 3C \& D and 4A). This value is significantly smaller than what was recently reported for $\mathrm{ZrC} / \mathrm{C}$ fibers by Li et al. (i.e., $500 \mathrm{~nm}$ to $1.5 \mu \mathrm{m}$ ) using polyzirconoxane and PAN. ${ }^{25}$ The homogenous fibers after carbothermal reduction did not exhibit any indication of a coreshell geometry and are composed of carbide nanocrystals embedded in a matrix of porous carbon (Fig. 3E). The free carbon content was measured to be 15 mass \% (Table 2) and we see a similar coating of graphene-like carbon layers around the metal carbide domains (Fig. 3F). The isotherm measured via gas sorption analysis shows a similar shape than for TiC/C (ESI, Fig. $\mathrm{S} 1 \mathrm{~A} \dagger$ ) and confirms the highly porous nature of the fibers and a surface area of $224 \mathrm{~m}^{2} \mathrm{~g}^{-1}$ (Table 2). This value is lower compared to the TiC/C-system; yet, we have to consider the higher density of zirconium carbide $\left(6.7 \mathrm{~g} \mathrm{~cm}^{-3}\right)$ compared to $\operatorname{TiC}\left(4.9 \mathrm{~g} \mathrm{~cm}^{-3}\right)$ and the lower free carbon content of 15 mass $\%$ compared to 32 mass \% with a high porosity.

Unlike the PVP in the TiBO system, CA and ACAC both participate in the condensation reaction as can be seen when comparing the FTIR spectra of the Zr(Iv)AcAc sol and ZrO fibers (Fig. 4D). The sol has peaks that are a combination of the constituents of the solution. There are almost no free hydroxyl groups as evidenced by the down shifted, almost indistinct $-\mathrm{OH}$
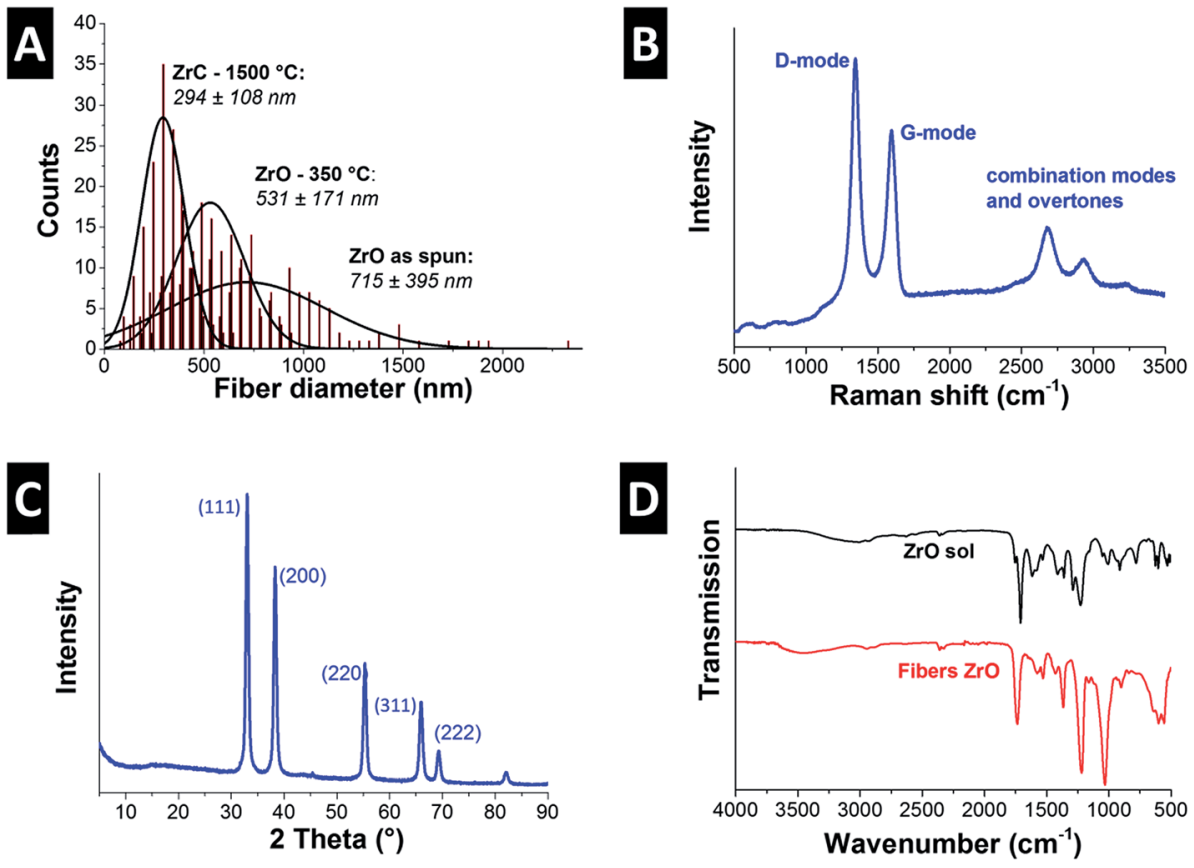

Fig. 4 (A) Fiber diameter distributions of the as spun fibers and heat treated fibers at $350{ }^{\circ} \mathrm{C}$ and $1500{ }^{\circ} \mathrm{C}$. (B) Raman spectrum and (C) X-ray diffractogram of the $\mathrm{ZrC} / \mathrm{C}$ nanocomposite fibers after heat treatment in argon at $1500^{\circ} \mathrm{C}$ for $2 \mathrm{~h}$. (D) FTIR spectra of the $\mathrm{ZrO}$ sol and the as spun fibers. 
peak at $3150 \mathrm{~cm}^{-1}$. Both AA and CA present $-\mathrm{OH}$ groups and the position of this peak suggests that there are several varieties of hydrogen bonding occurring in the solution. ${ }^{38}$ There are also two peaks assigned to the $\mathrm{C}=\mathrm{O}$ stretching mode: one is located at $1754 \mathrm{~cm}^{-1}$ associated with the carbonyl of the CA and the other more intense peak at $1711 \mathrm{~cm}^{-1}$ stems from the carbonyl of the AcAcACAC and AA. ${ }^{39}$ The peaks at 1576, 1530, and $1385 \mathrm{~cm}^{-1}$ relate to the $\mathrm{C}=\mathrm{O}$ symmetric and asymmetric stretch of the $\mathrm{Zr}$ (Iv)AcAc. ${ }^{40}$ In addition, the AcAc has two bands that arise due to mixed vibrations of the $-\mathrm{CH}_{3}$ and $-\mathrm{CH}_{2}$ out of plane bending interacting with $-\mathrm{OH}$ at 1421 and $1293 \mathrm{~cm}^{-1}$. Finally, we see a peak at $774 \mathrm{~cm}^{-1}$ due to the $-\mathrm{CH}_{3}$ out of plane rocking. ${ }^{39}$ The bands assigned to the $\mathrm{Zr}-\mathrm{O}$ are at 664 and $544 \mathrm{~cm}^{-1}$ and the peaks characteristic for CA are located at $1363 \mathrm{~cm}^{-1}$ for the $-\mathrm{CH}$ in plane bending, $1225 \mathrm{~cm}^{-1}$ for the $\mathrm{C}-\mathrm{O}$ stretch of the carboxylate, and $1160 \mathrm{~cm}^{-1}$ for the asymmetrical $\mathrm{C}-\mathrm{O}-\mathrm{C}$ (bridge) stretch. Finally, the pryanose ring $\mathrm{C}-\mathrm{O}-\mathrm{C}$ band is at $1051 \mathrm{~cm}^{-1}$ and the out of plane $-\mathrm{OH}$ is located at $600 \mathrm{~cm}^{-1} .^{38}$ The FTIR spectrum of ZrO fibers is very similar to the sol except the $-\mathrm{OH}$ stretch has shifted to higher wavenumbers from 3150 to $3495 \mathrm{~cm}^{-1}$ indicating there are more free $-\mathrm{OH}$ and less hydrogen bonding. The carbonyl peaks for the CA and AcAc have become indistinguishable and shifted to higher wave numbers (i.e., $1737 \mathrm{~cm}^{-1}$ ) indicating less hydrogen bonding to the AcAc. This is most likely due to the release of the AcAc from the $\mathrm{Zr}$ ion. A new peak at $1560 \mathrm{~cm}^{-1}$ is assigned to the $\mathrm{Zr}-\mathrm{O}-\mathrm{C}$ stretch from the CA forming a complex with the $\mathrm{Zr}$ ion. In addition, a new band at $840 \mathrm{~cm}^{-1}$ is due to the formation of $\mathrm{Zr}$ $\mathrm{O}-\mathrm{H}$, an intermediate step in the condensation reaction. There is also significant broadening of the bands below $750 \mathrm{~cm}^{-1}$ assigned to the formation of the $\mathrm{O}-\mathrm{Zr}-\mathrm{O}$ network. ${ }^{41}$

The remaining organic groups in the fiber, after the condensation reaction is completed, are converted to carbon during carbothermal reduction at $1500{ }^{\circ} \mathrm{C}$ for $2 \mathrm{~h}$. The resulting carbon is slightly more organized than the carbon in the TiC/C nanocomposite, as seen from TEM (Fig. 3F). This observation is supported by Raman spectroscopy (Fig. 4B, Table 2) where a $I_{\mathrm{D}} / I_{\mathrm{G}}$-ratio of 1.7 was indicative of a higher degree of carbon ordering. In the spectra, the $\mathrm{D}$-band is located at $1337 \pm 1.3 \mathrm{~cm}^{-1}$ (FWHM: $66 \pm 3.6 \mathrm{~cm}^{-1}$ ) and the G-band at $1594 \pm 0.5 \mathrm{~cm}^{-1}$ (FWHM: $63 \pm 2.2 \mathrm{~cm}^{-1}$ ). Besides the partially graphitic carbon, there is only one fully crystalline phase, namely ZrC, as identified with XRD (Fig. 4C). Rietveld analysis confirmed the space group $F m \overline{3} m$ typical for zirconium carbide and yielded a lattice parameter of $0.469 \mathrm{~nm}$ ( $c f$. PDF-35-0784: $0.469 \mathrm{~nm}){ }^{34}$ The calculated average coherence length was $65 \mathrm{~nm}$ which is in agreement with TEM micrographs (Fig. 3E and $\mathrm{F}$ ), but larger than what we observed for TiC/C nanocomposite fibers.

\subsection{Niobium carbide/carbon nanocomposite fibers}

Electrospinning $\mathrm{NbBO}$ with PVP was particularly challenging because of NbBO's strong tendency towards hydrolysis and condensation in the presence of ambient water. The solution droplet at the spinneret tip gels as soon as it is exposed to ambient moisture making it difficult to electrospin because the viscosity increases dramatically with time. As a result, the yield of fibers is very low and impossible to remove from the collector. To retard gelation, acetic anhydride was added to the spin dope because the $\mathrm{Ac}_{2} \mathrm{O}$ forms a bidentate ligand with the hydrolyzed niobium ion. ${ }^{42}$ This ligand inhibits the condensation reaction and, in effect, slows down the gelation rate so that the viscosity remains in a suitable range during electrospinning. This way, freestanding nonwoven textile mats can be effectively obtained.

Adopting the outlined synthesis procedure, we obtained smooth and cylindrical as-spun fibers with an average diameter of $124 \pm 74 \mathrm{~nm}$ (Fig. 5A and 7A). After pyrolysis at $400{ }^{\circ} \mathrm{C}$, the fibers maintain their smooth morphology and their diameter does not change significantly (Fig. 5B and 7A). Electron microscopy shows a uniform amorphous structure after heat treatment at $400{ }^{\circ} \mathrm{C}$ building a free-standing network of partially sintered fibers (Fig. 5B).

Analysis of the FTIR spectrum (Fig. 5C) of the NbBO sol is complicated because of overlapping bands arising from DMF, PVP, and the carboxylates from the $\mathrm{Ac}_{2} \mathrm{O}$. The bands in the 3500-3200 $\mathrm{cm}^{-1}$ can be assigned to $-\mathrm{NH}$ stretch of the PVP. In addition, absorbed water is present in the samples as evidenced by the free water rotations between $3900-3500 \mathrm{~cm}^{-1}$. The $-\mathrm{CH}_{2}$ and $-\mathrm{CH}_{3}$ stretch modes are assigned to the bands between $3000-2800 \mathrm{~cm}^{-1}$ and the prominent band at $1667 \mathrm{~cm}^{-1}$ is a convolution of the $\mathrm{C}=\mathrm{O}$ stretch peaks from the PVP, DMF, and $\mathrm{Ac}_{2} \mathrm{O}$. The bands assigned to the DMF below $1550 \mathrm{~cm}^{-1}$ are the $-\mathrm{CH}_{3}$ bending at $1506 \mathrm{~cm}^{-1}$, the symmetric bending of the methyl groups at $1394 \mathrm{~cm}^{-1}$, and the $-\mathrm{CN}$ at $1255 \mathrm{~cm}^{-1}$. These bands are not present in the spectra of the fibers because the DMF evaporates during electrospinning. PVP is present in both the sol and the fibers and the bands assigned to the PVP are the ring $\mathrm{CH}_{2}$ scissoring at 1489, 1456, and $1423 \mathrm{~cm}^{-1}$. The NbBO in the sol has assigned bands at $1472 \mathrm{~cm}^{-1}$ for the $-\mathrm{CH}$ bending and at $1086 \mathrm{~cm}^{-1}$ and $1055 \mathrm{~cm}^{-1}$ assigned to
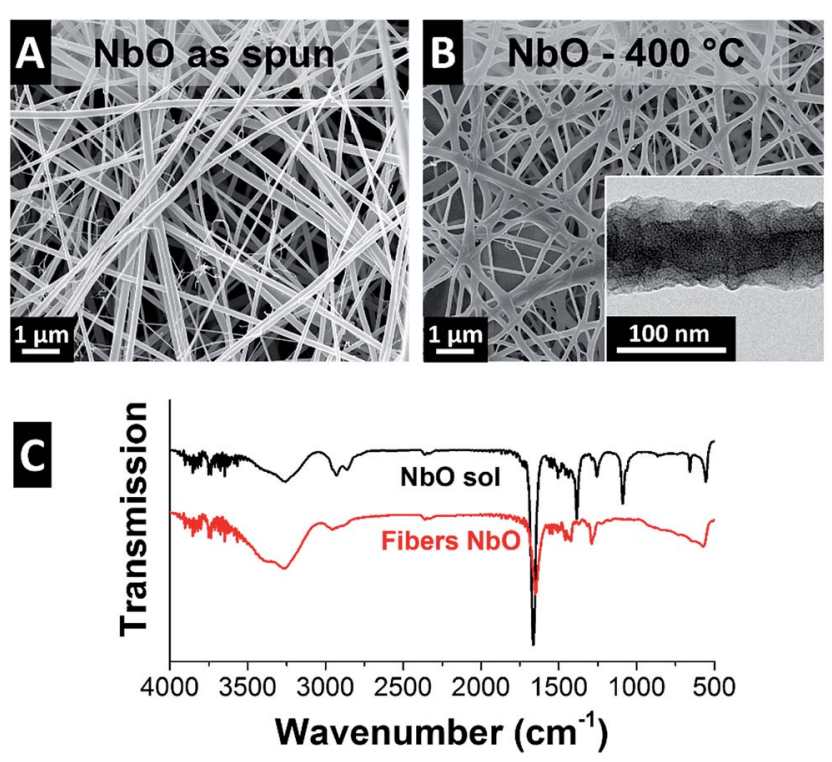

Fig. 5 Scanning electron and transmission electron micrographs of $(A)$ $\mathrm{NbO}$ as spun, and (B) after $400^{\circ} \mathrm{C}$ in argon. (C) FTIR spectra of the $\mathrm{NbO}$ sol and the as spun fibers. 

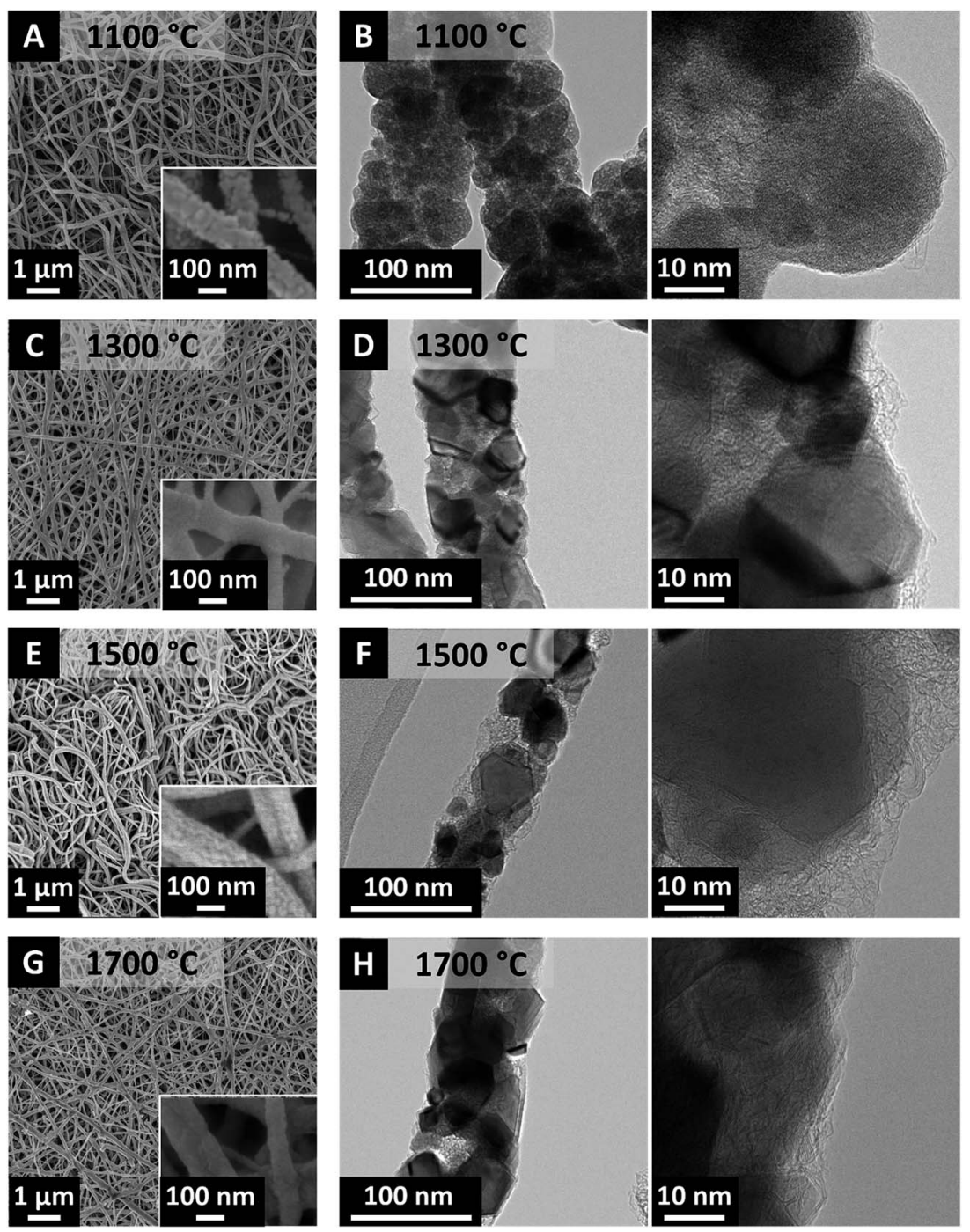

Fig. 6 (A, C, E and G) Scanning and (B, D, F and H) transmission electron micrographs of $\mathrm{NbC} / \mathrm{C}$ synthesized at $1100,1300,1500$, and $1700{ }^{\circ} \mathrm{C}$.

the $\mathrm{Nb}-\mathrm{O}$ in the butoxide. In addition, we see peaks assigned to $\mathrm{PVP}$ and $\mathrm{Nb}-\mathrm{O}$ from the butoxide between $1200-1000 \mathrm{~cm}^{-1}$ and also very broad peaks below $900 \mathrm{~cm}^{-1}$ assigned to the formation of poorly organized $\mathrm{NbO}^{43}$

Scanning electron microscopy presents cylindrical fibers with rough surface structure for all temperatures (Fig. 6). After carbothermal reduction at $1100{ }^{\circ} \mathrm{C}$, the fiber diameter decreases to $80 \pm 44 \mathrm{~nm}$ and further annealing at $1700^{\circ} \mathrm{C}$ reaches $65 \pm 36 \mathrm{~nm}$ fiber diameter (Fig. 7A). To the best of our knowledge, these are the thinnest such fibers reported in the literature so far.

To evaluate the effect of the carbothermal reduction temperature on the resulting carbide/carbon composite, fiber mats from the NbBO precursor were subjected to carbothermal reduction in argon at $1100,1300,1500$, or $1700{ }^{\circ} \mathrm{C}$. The free carbon content increases from 15 mass $\%$ for $1100{ }^{\circ} \mathrm{C}$ synthesis temperature to finally 29 mass $\%$ at $1700{ }^{\circ} \mathrm{C}$ (Table 2 ). The mats remained structurally intact after all temperatures; however, the material became more brittle as a result of increased carbon graphitization. The latter can be seen in the Raman spectra of the samples taken after each heat treatment (Fig. 7B).
Aligning with the results for TiC/C and $\mathrm{ZrC} / \mathrm{C}, \mathrm{NbC} / \mathrm{C}$ MCC also exhibits a uniform distribution of metal carbide nanocrystals engulfed by a matrix of disordered carbon (Fig. 6B, D, F and $\mathrm{H}$ ). Thermal treatment at $1100{ }^{\circ} \mathrm{C}$ yields highly disordered NbC particles (Fig. 6B), but the crystallinity increases significantly at $1300{ }^{\circ} \mathrm{C}$ (Fig. 6D) and larger crystals can be seen for temperatures of $1500{ }^{\circ} \mathrm{C}$ and $1700{ }^{\circ} \mathrm{C}$ (Fig. $6 \mathrm{~F}$ and $\mathrm{H}$ ). $\mathrm{NbC}$ nanocrystals were engulfed or covered by partially graphitic and disordered carbon coming from the carrier polymer. The nanocomposite character of $\mathrm{NbC} / \mathrm{C}$ nanofibers is corroborated by Raman spectroscopy (Fig. 7B, Table 2) and XRD measurements (Fig. 7C). These data identify partially graphitic carbon and nanocrystalline niobium carbide as the two components of the composite nanofibers. In particular, the Raman spectra exhibit the characteristic D- and G-modes indicating the presence of free-carbon and the disordered nature (Fig. 7B). Using different annealing temperatures, the $I_{\mathrm{D}} / I_{\mathrm{G}}$-ratio decreases dramatically from 2.6 to 1.2 from $1100{ }^{\circ} \mathrm{C}$ to $1700{ }^{\circ} \mathrm{C}$, indicating the increasing carbon ordering (Table 2). 

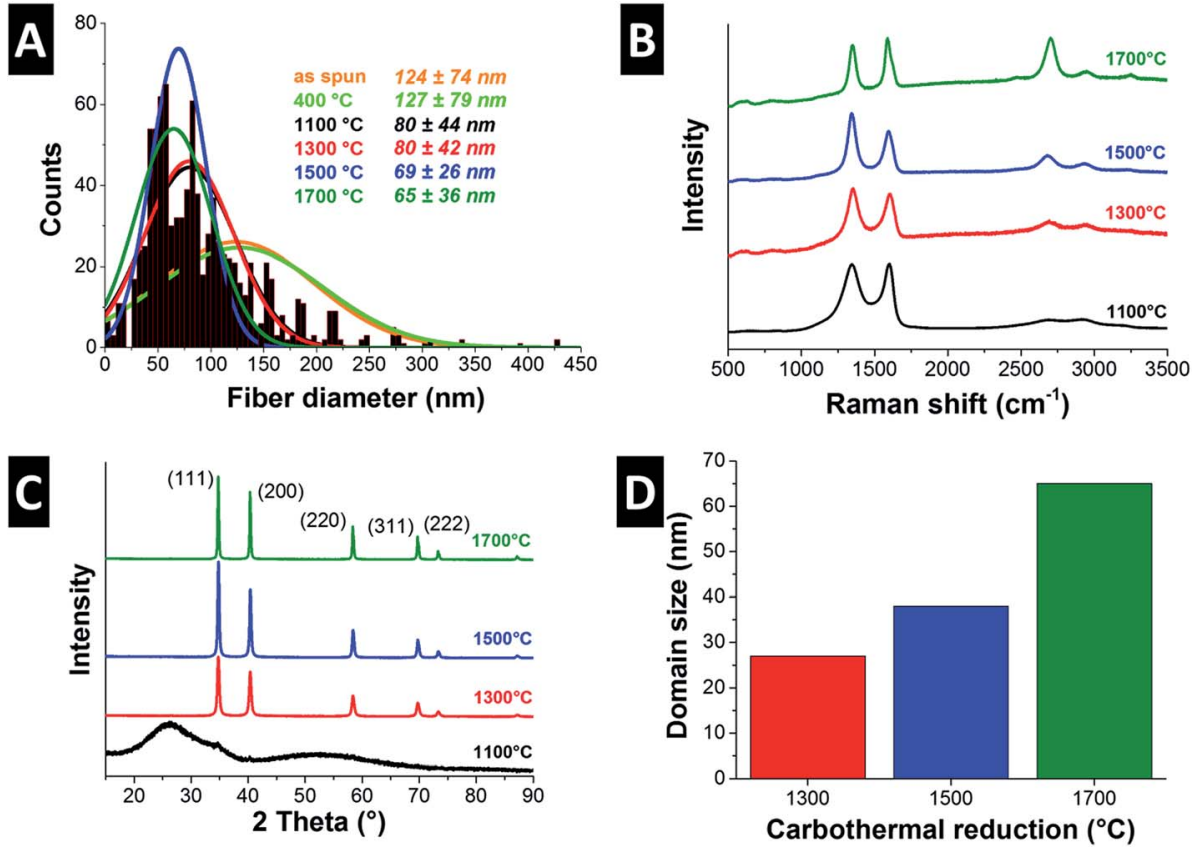

Fig. 7 (A) Fiber diameter distributions of $\mathrm{NbO}$ as spun and after different annealing temperatures. (B) Raman spectra, (C) XRD diffractograms, and (D) calculated $\mathrm{NbC}$ nanodomains sizes (i.e., average coherence length) for $\mathrm{NbC/C}$ nanocomposite nanofibers obtained after carbothermal reduction at different temperatures.

XRD data was subject to Rietveld analysis yielding an average coherence length of $38 \mathrm{~nm}$ and a lattice parameter of $0.447 \mathrm{~nm}$ for $F m \overline{3} m$ niobium carbide ( $c f$. PDF-38-1364: $0.447 \mathrm{~nm}$ ) (Fig. 7C and D). ${ }^{34}$ No changes in lattice spacing or crystal structure for the samples derived by carbothermal reduction at 1300,1500 , or $1700{ }^{\circ} \mathrm{C}$ were observed. In contrast, the XRD diffractogram after treatment at $1100{ }^{\circ} \mathrm{C}$ shows only broad peaks associated with partially graphitic carbon with a very small (111) peak emerging at around $34.8^{\circ} 2 \theta$. Partially graphitic carbon is also encountered for the other samples; yet, the high signal intensity of metal carbide peaks down-scale the carbon-related signal so strongly that it appears from first inspection that only metal carbides would be present. Thus, it is important to complement XRD with Raman data, as done in this study. We also see a continuous increase in the $\mathrm{NbC}$ domain size (i.e., average coherence length) with temperature, increasing from $27 \mathrm{~nm}$ at $1300{ }^{\circ} \mathrm{C}$ and $38 \mathrm{~nm}$ at $1500{ }^{\circ} \mathrm{C}$ to finally $65 \mathrm{~nm}$ at $1700^{\circ} \mathrm{C}$ what is in agreement with transmission electron microscopy (Fig. 7D).

Gas sorption analysis presents specific surface areas of $151 \mathrm{~m}^{2} \mathrm{~g}^{-1}$ for $1100{ }^{\circ} \mathrm{C}$ which decreases to $39 \mathrm{~m}^{2} \mathrm{~g}^{-1}$ for $1700^{\circ} \mathrm{C}$. Due to the more disordered carbon nature at $1100^{\circ} \mathrm{C}$, a higher pore volume is expected and shown by the gas sorption isotherms (ESI, Fig. S1B $\dagger$ ). NbC/C synthesized at $1100^{\circ} \mathrm{C}$ shows a characteristic type I isotherm shape indicating a microporous material. With increasing synthesis temperature the surface area decreases and the isotherm changes to type II with a small hysteresis characteristic for non-porous materials. These findings are in agreement with Raman spectroscopy presenting the transition of a highly disordered and porous material to a higher degree of carbon ordering with less pores at $1700{ }^{\circ} \mathrm{C}$.

\section{Conclusions}

In our study, we have presented the first comprehensive comparison of three different metal oxide/carbon nanocomposite fibers from a sol-gel-approach that can easily be converted to metal carbide/carbon nanocomposite nonwoven textiles via carbothermal reduction. In all cases, we obtained submicrometer-sized fibers; more precisely, we were able to obtain the following average fiber diameters: $294 \pm 108 \mathrm{~nm}$ for $\mathrm{ZrC} / \mathrm{C}, 122 \pm 28 \mathrm{~nm}$ for TiC/C, and $65 \pm 36 \mathrm{~nm}$ for $\mathrm{NbC} / \mathrm{C}$. All MCC nanocomposite fibers were homogenously composed of nanodomains of metal carbide in the range between $20 \mathrm{~nm}$ $(\mathrm{TiC} / \mathrm{C}), 38 \mathrm{~nm}(\mathrm{NbC} / \mathrm{C})$, and $65 \mathrm{~nm}(\mathrm{ZrC} / \mathrm{C})$ engulfed in a matrix of highly disordered carbon. This combination yields a relatively large specific surface area of $450 \mathrm{~m}^{2} \mathrm{~g}^{-1}$ for TiC/C $\left(1400{ }^{\circ} \mathrm{C}\right), 224 \mathrm{~m}^{2} \mathrm{~g}^{-1}$ for $\mathrm{ZrC} / \mathrm{C}\left(1500{ }^{\circ} \mathrm{C}\right)$, and $121 \mathrm{~m}^{2} \mathrm{~g}^{-1}$ for $\mathrm{NbC} / \mathrm{C}\left(1500^{\circ} \mathrm{C}\right)$. These high values are related to the presence of disordered and highly porous free carbon, varying between 15 and 32 mass\%. This array of MCC nanocomposite fibers was obtained in the form of freestanding nonwoven textiles which may serve as an ideal precursor for the synthesis of highly porous carbide-derived carbon electrodes for electrochemical applications.

\section{Acknowledgements}

The INM (www.inm-gmbh.de) is part of the Leibniz Research Alliance Energy Transition (LVE). We acknowledge funding from the German Federal Ministry for Research and Education (BMBF) in support of the nanoEES $S^{3 \mathrm{D}}$ project (award number 03EK3013) as part of the strategic funding initiative energy 
storage framework. LMF acknowledges financial support by the Manfred Lautenschläger Foundation via the MINT Excellence program. The authors thank Prof. Eduard Arzt for his continuing support and thank Dr Elmar Kroner for his support (both INM). Dr Mesut Aslan (INM) is thanked for his help with experimental work, Rudolf Karos (INM) for XRD measurements, and the group of Prof Frank Mücklich (Chair of Functional Materials, Saarland University) for supplying focused ion beam operations.

\section{References}

1 Z.-M. Huang, Y. Z. Zhang, M. Kotaki and S. Ramakrishna, Compos. Sci. Technol., 2003, 63, 2223-2253.

2 L. F. Zhang, A. Aboagye, A. Kelkar, C. L. Lai and H. Fong, J. Mater. Sci., 2014, 49, 463-480.

3 G. Wang, Q. Dong, Z. Ling, C. Pan, C. Yu and J. Qiu, J. Mater. Chem., 2012, 22, 21819-21823.

4 D. Li and Y. Xia, Nano Lett., 2003, 3, 555-560.

5 J. Watthanaarun, V. Pavarajarn and P. Supaphol, Sci. Technol. Adv. Mater., 2005, 6, 240.

6 L. Zhang, J. Hu, A. A. Voevodin and H. Fong, Nanoscale, 2010, 2, 1670-1673.

7 V. Presser, L. F. Zhang, J. J. Niu, J. McDonough, C. Perez, H. Fong and Y. Gogotsi, Adv. Energy Mater., 2011, 1, 423-430. 8 V. Presser, M. Heon and Y. Gogotsi, Adv. Funct. Mater., 2011, 21, 810-833.

9 Y. Gao, V. Presser, L. Zhang, J. J. Niu, J. K. McDonough, C. R. Pérez, H. Lin, H. Fong and Y. Gogotsi, J. Power Sources, 2012, 201, 368-375.

10 H. A. Liu and K. J. Balkus Jr, Mater. Lett., 2009, 63, 23612364.

11 M. Rose, E. Kockrick, I. Senkovska and S. Kaskel, Carbon, 2010, 48, 403-407.

12 A. Guo, M. Roso, M. Modesti, J. Liu and P. Colombo, J. Eur. Ceram. Soc., 2014, 34, 549-554.

13 A. Guo, M. Roso, M. Modesti, J. Liu and P. Colombo, J. Appl. Polym. Sci., 2014, 131, 39836.

14 C. Wessel, R. Ostermann, R. Dersch and B. M. Smarsly, J. Phys. Chem. C, 2010, 115, 362-372.

15 X. Zhang, V. Aravindan, P. S. Kumar, H. Liu, J. Sundaramurthy, S. Ramakrishna and S. Madhavi, Nanoscale, 2013, 5, 5973-5980.

16 C. Tekmen, A. Suslu and U. Cocen, Mater. Lett., 2008, 62, 4470-4472.

17 S. Cavaliere, S. Subianto, L. Chevallier, D. J. Jones and J. Roziere, Chem. Commun., 2011, 47, 6834-6836.

18 J. R. Martin, L. Borchardt, M. Oschatz, G. Mondin and S. Kaskel, Chem. Ing. Tech., 2013, 85, 1742-1748.
19 E. Davies, A. Lowe, M. Sterns, K. Fujihara and S. Ramakrishna, J. Am. Ceram. Soc., 2008, 91, 1115-1120.

20 C. Shao, H. Guan, Y. Liu, J. Gong, N. Yu and X. Yang, J. Cryst. Growth, 2004, 267, 380-384.

21 N. Dharmaraj, C. H. Kim and H. Y. Kim, Synth. React. Inorg., Met.-Org., Nano-Met. Chem., 2006, 36, 29-32.

22 E. Formo, M. S. Yavuz, E. P. Lee, L. Lane and Y. Xia, J. Mater. Chem., 2009, 19, 3878-3882.

23 Y. S. Nam, X. M. Cui, L. Jeong, J. Y. Lee and W. H. Park, Thin Solid Films, 2009, 517, 6531-6538.

24 X. M. Cui, Y. S. Nam, J. Y. Lee and W. H. Park, Mater. Lett., 2008, 62, 1961-1964.

25 F. Li, Z. Kang, X. Huang and G.-J. Zhang, Ceram. Int., 2014, 40, 10137-10141.

26 K. Nakane, M. Morinaga and N. Ogata, J. Mater. Sci., 2013, 48, 7774-7779.

27 M. Macias, A. Chacko, J. P. Ferraris and K. J. Balkus Jr, Microporous Mesoporous Mater., 2005, 86, 1-13.

28 P. Viswanathamurthi, N. Bhattarai, H. Y. Kim, D. R. Lee, S. R. Kim and M. A. Morris, Chem. Phys. Lett., 2003, 374, 79-84.

29 L. M. Berger, W. Gruner, E. Langholf and S. Stolle, Int. J. Refract. Met. Hard Mater., 1999, 17, 235-243.

30 W. S. Rasband, ImageJ, U. S. National Institutes of Health, Bethesda, Maryland, USA, 1997-2014.

31 P. Lespade, R. Al-Jishi and M. S. Dresselhaus, Carbon, 1982, 20, 427-431.

32 A. C. Ferrari and J. Robertson, Philos. Trans. R. Soc. London, Ser. A, 2004, 362, 2477-2512.

33 C. Portet, G. Yushin and Y. Gogotsi, J. Electrochem. Soc., 2008, 155, A531-A536.

34 H. Nowotny and G. Z. Glenk, Metallkd, 1947, 38.

35 F. X. Perrin, V. Nguyen and J. L. Vernet, J. Sol-Gel Sci. Technol., 2003, 28, 205-215.

36 D. C. Bradley, R. C. Mehrotra and D. P. Gaur, Metal Alkoxides, Harcourt Brace Jovanovich, London, 1978.

37 L. S. Taylor, F. W. Langkilde and G. Zografi, J. Pharm. Sci., 2001, 90, 888-901.

38 L. M. Ilharco and R. Brito de Barros, Langmuir, 2000, 16, 9331-9337.

39 S. F. Tayyari and F. Milani-nejad, Spectrochim. Acta, Part A, 2000, 56, 2679-2691.

40 R. C. Fay and T. J. Pinnavaia, Inorg. Chem., 1968, 7, 508-514. 41 B. S. Buyuktas and O. Aktas, Transition Met. Chem., 2006, 31, 56-61.

42 M. Nabavi, S. Doeuff, C. Sanchez and J. Livage, J. Non-Cryst. Solids, 1990, 121, 31-34.

43 Y.-n. Cai, S.-h. Yang, S.-m. Jin, H.-p. Yang, G.-f. Hou and J.-y. Xia, J. Cent. South Univ. Technol., 2011, 18, 73-77. 